\title{
Quality characteristics of the enhanced beef using winter mushroom juice
}

\author{
Yun-Sang Choi ${ }^{1}$, Kyung Jo ${ }^{2}$, Seonmin Lee $^{2}$, Hae In Yong ${ }^{1}$ and Samooel Jung ${ }^{2 \star}$ \\ ${ }^{1}$ Researcher Group of Food Processing, Korea Food Research Institute, Wanju 55365, Korea \\ ${ }^{2}$ Division of Animal and Dairy Science, Chungnam National University, Daejeon 34134, Korea
}

Received: Feb 16, 2020

Revised: Mar 16, 2020

Accepted: Mar 23, 2020

*Corresponding author

Samooel Jung

Division of Animal and Dairy Science,

Chungnam National University,

Daejeon 34134, Korea

Tel: +82-42-821-5774

E-mail: samooel@cnu.ac.kr

Copyright $\odot 2020$ Korean Society of Animal Sciences and Technology.

This is an Open Access article distributed under the terms of the

Creative Commons Attribution

Non-Commercial License (http:// creativecommons.org/licenses/by$\mathrm{nc} / 4.0 /$ ) which permits unrestricted non-commercial use, distribution, and reproduction in any medium, provided the original work is properly cited.

ORCID

Yun-Sang Choi

https://orcid.org/0000-0001-8060-6237

Kyung Jo

https://orcid.org/0000-0002-3006-5396

Seonmin Lee

https://orcid.org/0000-0002-5713-1795

Hae In Yong

https://orcid.org/0000-0003-0970-4496

Samooel Jung

https://orcid.org/0000-0002-8116-188X

Competing interests

No potential conflict of interest relevant to this article was reported.

Funding sources

This work was supported by the National Research Foundation of Korea (NRF) and a grant funded by the Korean government (MSIT) (No. 2019R1F1A1059255), and the 2017 Ottogi Foundation research program.

\section{Abstract}

This study investigated the quality properties of enhanced beef, manufactured by injecting the beef with a brine containing winter mushroom juice powder (WMJP). The enhanced beef was manufactured by injecting the eye of round with brine ( $15 \%$ by green weight). Four treatments consisted of control (no injection of brine) and three enhanced beef, EBS (brine containing $5 \mathrm{~g}$ sodium chloride per $\mathrm{kg}$ beef), EBW 0.2 (brine containing $5 \mathrm{~g}$ sodium chloride and $2 \mathrm{~g}$ WMJP per kg beef), and EBW 0.5 (brine containing $5 \mathrm{~g}$ sodium chloride and $5 \mathrm{~g}$ WMJP per kg beef), were tested. The effect of enhancement or WMJP on the quality properties of beef was evaluated during storage at $4^{\circ} \mathrm{C}$ for 1,5 , and 10 days. Total aerobic bacteria counts between the control and the enhanced beef, and among EBS, EBW 0.2, and EBW 0.5 were not significantly different after any storage period $(p>0.05)$. The $\mathrm{pH}$ of beef was not different between the control and the enhanced beef, and among enhanced beef at 1 and 5 days of storage $(p>0.05)$. However, it was higher in the enhanced beef than control, and EBW 0.2 and EBW 0.5 had higher $\mathrm{pH}$ than EBS after 10 days of storage $(p<0.05)$. The enhanced beef showed a high total loss at all storage days $(p<0.05)$. There were no differences in total loss among enhanced beef after any storage period $(p>0.05)$. The enhanced beef had no consistent differences in $L^{*}, a^{*}$, and $b^{*}$ values with control during storage, however, EBW 0.5 showed high color stability. The hardness of the enhanced beef was significantly lower than that of the control after 10 days of storage, although the values were lower at all storage stages. EBS 0.5 had the lowest thiobarbituric acid reactive substance (TBARS) value among cooked beef of all treatments at all storage days. The enhanced beef received higher scores in all sensory properties than control, and no negative effect of WMJP was found in the sensory quality of the enhanced beef. The use of winter mushroom juice can result in quality improvement in enhanced beef.

Keywords: Enhanced beef, Natural ingredient, Winter mushroom juice, Lipid oxidation

\section{INTRODUCTION}

Meat quality is affected by various intrinsic and extrinsic factors, and its improvement is important for consumer satisfaction [1-3]. Enhanced meat is manufactured by injecting brine into the meat to improve meat quality and conserve the appearance of fresh meat [3]. Sodium chloride is an essential in- 
Acknowledgements Not applicable.

Availability of data and material Upon reasonable request, the datasets of this study can be available from the corresponding author.

Authors' contributions Conceptualization: Choi YS, Jo K, Jung S Formal analysis: Jo K, Lee S, Yong HI. Writing - original draft: Choi YS. Writing - review \& editing: Jung S.

Ethics approval and consent to participate This article does not require IRB/IACUC approval because there are no human and animal participants. gredient in enhanced meat, as well as in other processed meat. It improves the texture of enhanced meat, increasing tenderness and juiciness by solubilizing myofibrillar proteins and increasing water holding capacity [4]. In addition, injection with sodium chloride inhibits the growth of microorganisms in meat products during storage [4]. Alkaline phosphate is also a general additive for enhanced meat because it improves texture through the dissociation of actomyosin and an increase in water holding capacity, and inhibits lipid oxidation and microbial growth by chelating the metal ions in meat products [4]. However, the use of synthetic additives in the manufacture of meat products has gradually lost consumer acceptance because of increasing concern about the negative effects on human health $[5,6]$. Therefore, natural ingredients that can be used for the enhancement of meat have been investigated $[3,7,8]$. However, despite displaying useful antioxidant and antimicrobial activities, many natural ingredients have detrimental side effects in meat products, such as the development of undesirable colors or flavors because of their intrinsically strong color and flavor [7,8].

Mushrooms are vegetables belonging to the fungal kingdom. They are well-known savory, functional, and nutraceutical foods [9]. The winter mushroom (Flammulina velutipes) is a white edible mushroom and contains various biological compounds. Many studies have reported that winter mushrooms have beneficial effects on human health in terms of antitumor, antiinflammation, and antioxidant activities [10,11]. Recent studies reported that the winter mushroom, as a natural ingredient, could improve the quality of comminuted meat products, such as pork and chicken sausages, by improving water holding capacity and inhibiting lipid oxidation [12,13]. In addition, no adverse effects on the sensory properties of meat products were found in these studies because of the white color and moderate flavor of winter mushrooms [12,13]. Based on the beneficial effects of winter mushrooms in comminuted meat products, we hypothesized that winter mushrooms could be a suitable natural ingredient to improve the quality of enhanced meat by increasing water holding capacity and antioxidative potential. Therefore, in this study, enhanced beef was manufactured by injecting beef with brine containing winter mushroom juice, and its quality properties were investigated.

\section{MATERIALS AND METHODS}

\section{Properties of winter mushroom juice powder (WMJP) \\ Preparation of WMJP}

Winter mushrooms were purchased from a local market (Daejeon, Korea). After removing the inedible part, the winter mushrooms were washed using tap water. The winter mushroom juice was extracted using a juicer (H-100S, Hurom, Gimhae, Korea), pasteurized at $63^{\circ} \mathrm{C}$ for $60 \mathrm{~min}$, and lyophilized (Bondiro, Ilshin, Seoul, Korea). WMJP was prepared three times on independent days.

\section{Total aerobic bacteria, coliform, and Escherichia coli counts in WMJP}

$\operatorname{WMJP}(5 \mathrm{~g})$ was blended with sterile saline $(45 \mathrm{~mL})$ for 2 min using a stomacher $\left(\right.$ BagMixer $^{\circledR} 400$; Interscience Ind., St. Nom, France). A series of decimal dilutions were prepared using sterile saline.

For measurement of the total aerobic bacteria count, $1 \mathrm{~mL}$ samples of the initial suspension $\left(10^{-1}\right.$ dilution) was transferred to petri dishes, and $15 \mathrm{~mL}$ liquid plate count agar (Difco Laboratories, Detroit, USA) was poured into each petri dish. These dilutions $(0.1 \mathrm{~mL})$ were spread onto solid plate count agar (Difco Laboratories). The plates were incubated at $30^{\circ} \mathrm{C}$ for $72 \mathrm{~h}$, and the microbial counts were expressed as the logarithm of colony-forming units per gram ( $\log \mathrm{CFU} / \mathrm{g})$.

Counts of total coliforms and E. coli were measured using E. coli/coliform count plates (3M Health Care, St. Paul, MN, USA). Each dilution $(1 \mathrm{~mL})$ was spread on a plate, and the plate was 
incubated at $37^{\circ} \mathrm{C}$ for $24 \mathrm{~h}$. The total coliforms and $E$. coli counts were expressed as Log CFU/g.

\section{pH and $\alpha$-amino group content of winter mushroom juice}

The $\mathrm{pH}$ and $\alpha$-amino group content ( $\mu \mathrm{M} / \mathrm{g}$ protein) of the winter mushroom juice were measured before lyophilization. A pH meter (SevenEasy, Mettler-Toledo Inti, Schwerzenbach, Switzerland) was used for the measurement of the winter mushroom juice $\mathrm{pH}$.

The $\alpha$-amino group content ( $\mu \mathrm{M} / \mathrm{g}$ protein) of the winter mushroom juice was measured using an o-phthal-dialdehyde (OPA) method [14]. The Kjeldhal method (AOAC, 2010) was used for the crude protein analysis of the winter mushroom juice.

\section{Antioxidant potential of WMJP}

WMJP $(0.5 \mathrm{~g})$ and $70 \%$ methanol were mixed and the final volume adjusted to $50 \mathrm{~mL}$ for measuring the total phenolic content, 1,1-diphenyl-2-picrylhydrazyl (DPPH) radical scavenging activity, 2,2-azinobis-(3 ethylbenzothiazoline-6-sulfonic acid) $\left(\mathrm{ABTS}^{+}\right)$reducing activity, and reducing power.

Total phenolic content was estimated using the Folin-Ciocalteu method [15]. DPPH radical scavenging activity and $\mathrm{ABTS}^{+}$reducing activity were determined following the method described by Jung et al. [15] and Erel [16], respectively. The reducing power was determined according to the method used in the study of Oyaizu [17].

Ergothioneine was extracted from the WMJP [18]. The ergothioneine content was analyzed by high-performance liquid chromatography (1200 series, Agilent Technologies, USA). A Luna HILIC column $(150 \times 4.6 \mathrm{~mm}, 3 \mu \mathrm{m}$ particles $)$ was used for analysis and the mobile phase included acetonitrile (A) and $20 \mathrm{mM}$ ammonium acetate (pH adjusted to 6.0 with acetic acid) (B). The flow rate of the mobile phase was $1 \mathrm{~mL} / \mathrm{min}$, with an isocratic elution profile of $\mathrm{A}: \mathrm{B}=85: 15$ for 20 min. The column temperature was maintained at $40^{\circ} \mathrm{C}$, and the UV wavelength used to monitor the signals was $254 \mathrm{~nm}$.

\section{Quality properties of WMJP-enhanced beef Manufacture of enhanced beef}

Six eye of rounds (semitendinosus muscle) from three steer carcasses (7 days after slaughter) were obtained from a local market (Daejeon, Korea). The two muscles from each carcass were divided into four parts each and each part assigned to one of four treatments (control, no injection of brine; EBS, injection of brine containing $5 \mathrm{~g}$ sodium chloride per $\mathrm{kg}$ beef; EBW 0.2, injection of brine containing $5 \mathrm{~g}$ sodium chloride and $2 \mathrm{~g}$ WMJP per kg beef; and EBW 0.5, injection of brine containing $5 \mathrm{~g}$ sodium chloride and $5 \mathrm{~g}$ WMJP per $\mathrm{kg}$ beef). The appropriate amounts of sodium chloride and WMJP were dissolved in sterilized distilled water before injection. The beef was weighed individually and injected with brine (15\% by green weight) using a multiple-needle injector. The beef from each carcass were assigned to each batch, and the manufacture of enhanced beef was repeated three times in independent three batches. The enhanced beef was sealed in polyethylene bags and stored in a refrigerator at $4{ }^{\circ} \mathrm{C}$ for $24 \mathrm{~h}$. Each enhanced beef sample was then cut into three pieces, which were individually vacuum packaged, and stored in a refrigerator at $4^{\circ} \mathrm{C}$ for 1,5 , or 10 days.

Total aerobic bacteria, coliform, and Escherichia coli counts in enhanced beef The beef $(25 \mathrm{~g})$ was blended with sterile saline $(225 \mathrm{~mL})$ for $2 \mathrm{~min}$ using a stomacher (BagMixer ${ }^{\circledR}$ $400)$ and a series of decimal dilutions were prepared using sterile saline. The measurements of total aerobic bacteria, coliforms, and $E$. coli in the enhanced beef were performed following the methods 
described above.

\section{pH and total loss of enhanced beef}

The beef $(3 \mathrm{~g})$ were mixed with $27 \mathrm{~mL}$ distilled water and homogenized (T25 basic, IKA GmbH \& Co. KG, Germany) at 1,130×g for $1 \mathrm{~min}$. The homogenate was centrifuged (1580R) at 2,265 ×g for $10 \mathrm{~min}$ and the supernatants were recovered by gravity filtration using Whatman No. 4 filter paper (Whatman, UK). The $\mathrm{pH}$ of each filtrate was measured with a $\mathrm{pH}$ meter (SevenEasy) which was pre-calibrated using standard buffers ( $\mathrm{pH} 4.01,7.00$, and 9.21).

The total loss of beef was measured based on the drip loss and cooking loss. The drip loss represents the fluid lost during storage, and was calculated as the difference between the total weight of the beef and the weight of the fluid exudate. The beef was vacuum packaged, and cooked at $85^{\circ} \mathrm{C}$ for $20 \mathrm{~min}$ in a water bath. The cooking loss was calculated as the difference between the weight of the raw beef and the weight of the cooked beef. The total loss represents the weight lost from the original weight of the beef by dripping and cooking.

\section{Instrumental color of enhanced beef}

The beef was bloomed at $20^{\circ} \mathrm{C}$ for $30 \mathrm{~min}$ in aerobic conditions. The color parameters (CIE L*, a*, and $\mathrm{b}^{*}$ ) of the beef were measured using a colorimeter (CM-3500d, Minolta, Japan). Measurements were taken, perpendicular to the surface of the beef with an illumination area $30 \mathrm{~mm}$ in diameter, at two different locations per sample. The results were analyzed using Spectra Magic Software (Minolta, Japan).

\section{Lipid oxidation of enhanced beef}

Lipid oxidation in the beef was measured after cooking at $85^{\circ} \mathrm{C}$ for $20 \mathrm{~min}$ in a water bath. It was monitored by detecting malondialdehyde with 2-thiobarbituric acid (TBA) [19].

\section{Sensory evaluation of enhanced beef}

Sensory evaluation of the enhanced beef was conducted after 10 days of storage. The sensory properties were evaluated three times in three independent sessions and each session included beef samples from each batch. A group of 15 panelists was used. Beef from all three batches was cut regularly and cooked using an electric grill (EMG-533; Aijia Electrical Appliance, China) for $90 \mathrm{~s}$. The cooked beef was served to the panelists on a white glass plate. The scoring for each sample was done on a single sheet using a 9-point hedonic scale $(1=$ strongly dislike, $9=$ strongly like). The color, flavor, taste, texture (tenderness and juiciness), and overall acceptability were evaluated.

\section{Statistical analysis}

This study was conducted in triplicate. The properties of the WMJP were statistically analyzed by $t$-test. The quality of the enhanced beef was statistically analyzed using mixed models under a randomized complete block design (with each batch corresponding to a block). The main effect of the statistical model was set as the enhancement sources. The block of the analyses and the panelist and session of sensory evaluation were included in the model as random effects. The results were expressed as the least-square mean and standard error of the least-square mean, and specific comparisons were performed using Tukey's multiple-range test when the main effect was significant ( $p$ $<0.05$ ). SAS software (version 9.4, SAS Institute, Cary, NC, USA) was used for statistical analyses. 


\section{RESULTS AND DISCUSSION}

\section{Properties of WMJP}

Natural ingredients are generally contaminated by various microorganisms, and their injection may spoil enhanced meat that is unpasteurized during storage. The winter mushroom juice was pasteurized at $63^{\circ} \mathrm{C}$ for $1 \mathrm{~h}$, and the total aerobic bacteria, E. coli, and coliforms in WMJP were lower than the detection limit ( 1 Log CFU/g) (Table 1).

The $\mathrm{pH}$ of the WMJP increased significantly from 6.45 to 6.56 after heat pasteurization (Table 1). This result could be explained by the exposure of basic amino acids to heating. The comparably high $\mathrm{pH}$ of winter mushrooms is related to their high content of basic amino acids [12,20]. Previous studies found a 4 -fold increase in total free amino acids in mushrooms after boiling at $60^{\circ} \mathrm{C}$ for $4 \mathrm{~h}$, and this was affected by cooking methods [21]. However, the free amino acid content in the WMJP used in the present study might not change with heat pasteurization, based on the lack of change detected in the $\alpha$-amino group content of the WMJP (Table 1). Increases in the $\mathrm{pH}$ of foods after cooking have been generally reported, and are caused by the exposure of basic amino acids as the proteins unfold [22,23]. Therefore, the increase in the $\mathrm{pH}$ of the winter mushroom juice after heat pasteurization might be caused by the exposure of basic amino acids with the unfolding of proteins. The increased $\mathrm{pH}$ of the WMJP would be a beneficial property for the enhancement of beef, because a higher $\mathrm{pH}$ in meat products after additive injection leads to improved water holding capacity by increasing the net charge effects of myofibrillar proteins $[12,13]$.

Phenolic compounds are well-known antioxidants contained in most natural plants and ergothioneine is an antioxidative amino acid synthesized only in certain fungi [18]. The phenolic compound and ergothioneine content in the WMJP were not different after heat pasteurization (Table 1). In addition, DPPH radical scavenging activity, $\mathrm{ABTS}^{+}$reducing activity, and reducing power were not significantly different between raw and heat-pasteurized WMJP. A previous study reported that thermal processing of mushrooms decreases their phenolic compound content by heat degradation and that thermal resistance differs among phenolic compounds [24]. However, the an-

Table 1. Properties of the lyophilized powder of winter mushroom juice

\begin{tabular}{|c|c|c|c|}
\hline & \multicolumn{2}{|c|}{ Winter mushroom juice } & \multirow{2}{*}{ SEM } \\
\hline & Raw & Heat pasteurization & \\
\hline \multicolumn{4}{|l|}{ Bacteria counts (Log CFU/g) } \\
\hline Total aerobic bacteria & 5.01 & $N D^{1)}$ & - \\
\hline Coliform & 2.53 & ND & - \\
\hline Escherichia coli & ND & ND & \\
\hline $\mathrm{pH}$ & $6.45^{\mathrm{b}}$ & $6.56^{\mathrm{a}}$ & 0.011 \\
\hline$\alpha$-Amino group content ( $\mu \mathrm{M} / \mathrm{g}$ protein) & 2.61 & 2.59 & 0.038 \\
\hline \multicolumn{4}{|l|}{ Antioxidant potential } \\
\hline Phenolic content (g GAE/kg) & 5.75 & 5.73 & 0.136 \\
\hline Ergothioneine content (g/kg) & 2.43 & 2.53 & 0.042 \\
\hline DPPH $(\%)^{2)}$ & 78.79 & 76.38 & 1.085 \\
\hline $\operatorname{ABTS}^{+}(\%)^{3)}$ & 53.77 & 56.38 & 1.183 \\
\hline Reducing power & 0.89 & 0.92 & 0.012 \\
\hline
\end{tabular}

${ }^{1 /}$ Microorganism counts were lower than detection limit (1 Log CFU/g).

${ }^{2)} 1,1$-diphenyl-2-picrylhydrazyl radical $(0.2 \mathrm{mM})$ scavenging activity of winter mushroom juice powder $(20 \mathrm{mg} / \mathrm{mL}$ ).

${ }^{3 / 2}$,2-azinobis-(3 ethylbenzothiazoline-6-sulfonic acid) (7 mM) reducing activity of winter mushroom juice powder ( $\left.20 \mathrm{mg} / \mathrm{mL}\right)$.

a,b Different letters in the same row indicate significant differences between means $(p<0.05)$.

SEM, standard error of the mean. 
tioxidant potential of WMJP was not negatively affected by heat pasteurization at $63^{\circ} \mathrm{C}$ for $1 \mathrm{~h}$.

\section{Microbial counts of enhanced beef}

Coliforms and $E$. coli were lower than the detection limit $(1 \mathrm{Log} C F U / g)$ in all the beef samples, regardless of treatment (data not shown). The total aerobic bacteria counts did not differ between the control and enhanced beef samples for any storage period (Table 2). Sodium chloride is a wellknown antimicrobial compound that inhibits the growth of microorganisms by causing osmotic stress to the microorganisms and decreasing the water activity of foods $[25,26]$. All enhanced beef treatments contained $0.5 \%$ sodium chloride in this study. However, $0.5 \%$ sodium chloride is insufficient for the inhibition of microbial growth [25].

EBW 0.2 and EBW 0.5, which contained sodium chloride and WMJP, showed similar total aerobic bacteria counts to EBS, which contained only sodium chloride, after 1 and 5 days of storage. The total aerobic bacteria count of EBW 0.2 was significantly higher than that of EBS after 10 days of storage. However, the differences were less than $1 \mathrm{Log} C F U / g$.

\section{$\mathrm{pH}$ and total loss of enhanced beef}

The $\mathrm{pH}$ of the enhanced beef did not differ from that of the control after 1 or 5 days of storage (Table 3). In addition, no differences in $\mathrm{pH}$ were found among the enhanced beef samples after 1 or 5 days of storage. After 10 days of storage, EBW 0.2 and EBW 0.5 showed higher $\mathrm{pHs}$ than EBS. This result might be related to the higher growth of microorganisms in EBW 0.2 and EBW 0.5 than in $\mathrm{EBS}$. The $\mathrm{pH}$ of the meat could be increased owing to protein degradation by the protases released by microorganisms during storage [2]. However, no increases in $\mathrm{pH}$ were found in any of the beef samples during storage, except for EBW 0.5.

The $\mathrm{pH}$ of meat is an important quality property because a high $\mathrm{pH}$ leads to a high water holding capacity in meat [12,27]. Jo et al. [12] and Choe et al. [13] found that the addition of $0.5 \%$ winter mushroom powder to chicken and pork sausages increased the $\mathrm{pH}$ of the sausages. However, the injection of $0.5 \%$ WMJP into the beef samples in this study had no significant effects on the beef $\mathrm{pH}$, although the $\mathrm{pH}$ of EBW 0.5 was numerically higher than that of the control. The buffering capacity of meat is different depending on the muscles and species in question [28]. Therefore, the

Table 2. Total aerobic bacteria counts (Log CFU/g) of the enhanced beef during storage at $4^{\circ} \mathrm{C}$

\begin{tabular}{lcccc}
\hline \multirow{2}{*}{ Treatment $^{1}$} & \multicolumn{3}{c}{ Storage days } & SEM \\
\cline { 2 - 4 } & $\mathbf{1}$ & $\mathbf{5}$ & $\mathbf{1 0}$ & \\
\hline Enhancement & $1.93^{\mathrm{z}}$ & $2.53^{\mathrm{y}}$ & $3.53^{\mathrm{x}}$ & 0.206 \\
Control & $1.74^{\mathrm{z}}$ & $2.60^{\mathrm{y}}$ & $3.67^{\mathrm{x}}$ & 0.105 \\
Enhanced beef & 0.118 & 0.254 & 0.239 & \\
SEM & & & & 0.152 \\
\hline Source & $1.79^{z}$ & $2.71^{\mathrm{y}}$ & $3.26^{\mathrm{bx}}$ & 0.178 \\
EBS & $1.69^{\mathrm{z}}$ & $2.91^{\mathrm{y}}$ & $4.08^{\mathrm{ax}}$ & 0.272 \\
EBW 0.2 & $1.72^{\mathrm{y}}$ & $2.17^{\mathrm{y}}$ & $3.69^{\mathrm{abx}}$ & \\
EBW 0.5 & 0.143 & 0.318 & 0.178 & \\
SEM & & & & \\
\hline
\end{tabular}

${ }^{1)}$ Control: no enhanced beef; EBS: the enhanced beef by $0.5 \%(\mathrm{w} / \mathrm{w})$ sodium chloride; EBW 0.2 : the enhanced beef by $0.5 \%$ $(\mathrm{w} / \mathrm{w})$ sodium chloride and $0.2 \%(\mathrm{w} / \mathrm{w})$ powder of winter mushroom juice; EBW 0.5 : the enhanced beef by $0.5 \%$ (w/w) sodium chloride and $0.5 \%(\mathrm{w} / \mathrm{w})$ powder of winter mushroom juice.

${ }^{a, b}$ Different letters in the same column indicate significant differences between means $(p<0.05)$.

${ }^{x-z}$ Different letters in the same row indicate significant differences between means $(p<0.05)$.

SEM, standard error of the least square mean. 
Table 3. $\mathrm{pH}$ and total loss (\%) of the enhanced beef during storage at $4^{\circ} \mathrm{C}$

\begin{tabular}{|c|c|c|c|c|}
\hline \multirow{2}{*}{ Treatment $^{1)}$} & \multicolumn{3}{|c|}{ Storage days } & \multirow{2}{*}{ SEM } \\
\hline & 1 & 5 & 10 & \\
\hline \multicolumn{5}{|l|}{$\mathrm{pH}$} \\
\hline \multicolumn{5}{|l|}{ Enhancement } \\
\hline Control & 5.57 & 5.59 & $5.56^{\mathrm{b}}$ & 0.018 \\
\hline Enhanced beef & 5.62 & 5.60 & $5.64^{\mathrm{a}}$ & 0.024 \\
\hline SEM & 0.041 & 0.036 & 0.036 & \\
\hline \multicolumn{5}{|l|}{ Source } \\
\hline EBS & 5.56 & 5.56 & $5.57^{\mathrm{b}}$ & 0.013 \\
\hline EBW 0.2 & 5.65 & 5.60 & $5.64^{\mathrm{a}}$ & 0.030 \\
\hline EBW 0.5 & $5.65^{y}$ & $5.65^{y}$ & $5.70^{\mathrm{ax}}$ & 0.018 \\
\hline SEM & 0.038 & 0.037 & 0.024 & \\
\hline \multicolumn{5}{|l|}{ Total loss (\%) } \\
\hline \multicolumn{5}{|l|}{ Enhancement } \\
\hline Control & $31.61^{\mathrm{bx}}$ & $29.90^{\text {by }}$ & $30.50^{\mathrm{bxy}}$ & 0.481 \\
\hline Enhanced beef & $38.64^{\mathrm{ax}}$ & $34.34^{a y}$ & $35.21^{\text {ay }}$ & 0.876 \\
\hline SEM & 1.145 & 1.125 & 1.032 & \\
\hline \multicolumn{5}{|l|}{ Source } \\
\hline EBS & $37.58^{x}$ & $34.61^{y}$ & $36.03^{x y}$ & 1.143 \\
\hline EBW 0.2 & $40.32^{x}$ & $34.27^{y}$ & $35.16^{y}$ & 1.618 \\
\hline EBW 0.5 & 38.02 & 34.16 & 34.43 & 1.594 \\
\hline SEM & 1.200 & 1.543 & 1.366 & \\
\hline
\end{tabular}

${ }^{11}$ Control: no enhanced beef; EBS: the enhanced beef by $0.5 \%(\mathrm{w} / \mathrm{w})$ sodium chloride; EBW 0.2 : the enhanced beef by $0.5 \%$ (w/w) sodium chloride and $0.2 \%$ (w/w) powder of winter mushroom juice; EBW 0.5 : the enhanced beef by $0.5 \%$ (w/w) sodium chloride and $0.5 \%(\mathrm{w} / \mathrm{w})$ powder of winter mushroom juice.

${ }^{a, b}$ Different letters in the same column indicate significant differences between means $(p<0.05)$.

${ }^{x-z}$ Different letters in the same row indicate significant differences between means $(p<0.05)$.

SEM, standard error of the least square mean.

effect of winter mushrooms on the $\mathrm{pH}$ of meat products might differ between our results and those of previous studies.

The total loss caused by fluid release from beef during storage and cooking was significantly higher in the enhanced beef than in the control on all storage days (Table 3). Although the $\mathrm{pH}$ did not differ between the control and the enhanced beef in the present study, both drip loss and cooking loss were higher in the enhanced beef than in the control $(p<0.05$, data not shown). The higher drip and cooking losses in the enhanced beef were caused, partly, by the release of injected brine [3]. The total loss did not differ among the enhanced beef samples regardless of storage period. In the present study, the whole semitendinosus muscle was stored for 1 day after brine injection, and was then cut and stored for various lengths of time. The highest total loss of enhanced beef was found after 1 day of storage, regardless of treatment. It was caused by the initial release of injected brine from the enhanced beef. The total loss of beef after 10 days of storage (except for EBW 0.2) was no different than that after 1 day of storage. This result could be explained by increasing drip losses with increasing storage time [3].

\section{Color of enhanced beef}

There were no differences in $\mathrm{L}^{*}$ values between the control and the enhanced beef on any storage day (Table 4). The $a^{*}$ and $b^{*}$ values of the enhanced beef were numerically lower than those of the 
Table 4. Instrumental color (CIE $L^{*}, a^{*}$, and $b^{*}$ values) of the enhanced beef during storage at $4^{\circ} \mathrm{C}$

\begin{tabular}{|c|c|c|c|c|}
\hline \multirow{2}{*}{ Treatment $^{1)}$} & \multicolumn{3}{|c|}{ Storage days } & \multirow{2}{*}{ SEM } \\
\hline & 1 & 5 & 10 & \\
\hline \multicolumn{5}{|l|}{$L^{*}$ value } \\
\hline \multicolumn{5}{|l|}{ Enhancement } \\
\hline Control & 35.82 & 36.27 & 36.77 & 1.040 \\
\hline Enhanced beef & $35.24^{y}$ & $38.39^{x}$ & $37.55^{\times}$ & 0.835 \\
\hline SEM & 1.228 & 1.153 & 0.885 & \\
\hline \multicolumn{5}{|l|}{ Source } \\
\hline EBS & $34.52^{y}$ & $38.95^{x}$ & $37.74^{x}$ & 1.132 \\
\hline EBW 0.2 & $35.72^{y}$ & $39.27^{x}$ & $37.62^{x y}$ & 1.298 \\
\hline EBW 0.5 & 35.64 & 36.94 & 37.30 & 1.374 \\
\hline SEM & 1.651 & 1.233 & 1.192 & \\
\hline \multicolumn{5}{|l|}{$a^{*}$ value } \\
\hline \multicolumn{5}{|l|}{ Enhancement } \\
\hline Control & $24.66^{x}$ & $24.95^{\mathrm{ax}}$ & $22.62^{y}$ & 0.697 \\
\hline Enhanced beef & $23.35^{x}$ & $18.98^{\text {by }}$ & $21.15^{x y}$ & 0.942 \\
\hline SEM & 1.231 & 1.700 & 0.855 & \\
\hline \multicolumn{5}{|l|}{ Source } \\
\hline EBS & $24.09^{x}$ & $15.37^{\text {by }}$ & $21.18^{x}$ & 1.311 \\
\hline EBW 0.2 & $23.76^{x}$ & $21.56^{\mathrm{axy}}$ & $20.58^{y}$ & 1.775 \\
\hline EBW 0.5 & 22.05 & $20.84^{\mathrm{a}}$ & 21.69 & 1.001 \\
\hline SEM & 1.111 & 1.612 & 1.214 & \\
\hline \multicolumn{5}{|l|}{$b^{*}$ value } \\
\hline \multicolumn{5}{|l|}{ Enhancement } \\
\hline Control & 22.57 & $23.81^{\mathrm{a}}$ & 22.71 & 0.597 \\
\hline Enhanced beef & $22.48^{x}$ & $20.75^{\text {by }}$ & $22.17^{x}$ & 0.549 \\
\hline SEM & 0.653 & 0.850 & 0.468 & \\
\hline \multicolumn{5}{|l|}{ Source } \\
\hline EBS & $22.73^{x}$ & $19.28^{y}$ & $21.91^{x}$ & 0.795 \\
\hline EBW 0.2 & 22.75 & 21.59 & 21.99 & 0.843 \\
\hline EBW 0.5 & 21.87 & 21.40 & 22.62 & 0.851 \\
\hline SEM & 0.891 & 0.988 & 0.592 & \\
\hline
\end{tabular}

${ }^{1)}$ Control: no enhanced beef; EBS: the enhanced beef by $0.5 \%(\mathrm{w} / \mathrm{w})$ sodium chloride; EBW 0.2 : the enhanced beef by $0.5 \%$ $(\mathrm{w} / \mathrm{w})$ sodium chloride and $0.2 \%(\mathrm{w} / \mathrm{w})$ powder of winter mushroom juice; EBW 0.5 : the enhanced beef by $0.5 \%$ (w/w) sodium chloride and $0.5 \%(\mathrm{w} / \mathrm{w})$ powder of winter mushroom juice.

${ }^{a-b}$ Different letters in the same column indicate significant differences between means $(p<0.05)$.

${ }^{x-z}$ Different letters in the same row indicate significant differences between means $(p<0.05)$.

SEM, standard error of the least square mean.

control on all storage days, although the differences were only significant after 5 days of storage. This result might be attributed to the release of myoglobin with dripping, which was higher in the enhanced beef in the present study. Myoglobin, a major meat pigment, is a water-soluble protein and the release of myoglobin with dripping can results in a decrease in redness [30].

The whole vegetables or their extracts have been used as natural ingredients for improving the quality of meat products. However, the intrinsic colors of vegetables have a negative effect on the color of meat products $[6,7,29,31]$. In the present study, the $\mathrm{L}^{*}, \mathrm{a}^{*}$, and $\mathrm{b}^{*}$ values of the enhanced beef did not differ, regardless of the use of WMJP, over any storage period. The injection of WMJP 
had no negative effect on the color of the enhanced beef. This was attributed to the white color of winter mushrooms. Previous studies reported that the addition of winter mushroom powder resulted in no color changes to meat products [6,7].

During storage, the control showed no changes in $\mathrm{L}^{*}$ or $\mathrm{b}^{*}$ values. However, the $\mathrm{a}^{*}$ value of the control was significantly lower after 10 days of storage than it was after 1 or 5 days of storage. In the enhanced beef, the EBS and EBW 0.2 displayed low color stability; the $\mathrm{L}^{*}$ and $\mathrm{a}^{*}$ values changed significantly during storage. However, EBW 0.5 showed high color stability with no changes in L*, $\mathrm{a}^{*}$, or $\mathrm{b}^{*}$ values during 10 days of storage. The oxidative stability of beef is a factor in its color stability during storage, and low oxidative stability results in low color stability [32]. In the present study, the WMJP contained polyphenols and ergothioneine, and showed antioxidant activity (Table 1). Therefore, EBW 0.5 might have higher color stability as well as higher oxidative stability than the other beef samples.

\section{Texture properties of enhanced beef}

The texture properties such as the hardness, springiness, chewiness, gumminess, and cohesiveness of the cooked beef were measured (Table 5). There were no significant differences in springiness or cohesiveness among any treatments or storage periods (data not shown). The hardness of the enhanced beef was significantly lower than that of the control after 10 days of storage, although it was numerically lower on all storage days. The marination of the meat and injection with sodium chloride improves the tenderness of beef because it solubilizes myofibrillar proteins [33,34]. Therefore, the hardness of the enhanced beef might have been decreased by the gradual solubilization of muscle proteins after 10 days of storage. The injection of WMJP had no determinate effect on the hardness of the enhanced beef. The lowest hardness for the enhanced beef was found in EBW 0.5 after 1 day of storage $(p<0.05)$. However, the hardness did not differ among the enhanced beef samples after 5 or 10 days of storage. The chewiness and gumminess of the beef gave similar results as hardness because chewiness and gumminess were calculated based on hardness values.

The texture properties of the beef did not change during storage. Although significant differences in hardness and gumminess were found in EBW 0.5 during storage, the differences in hardness and gumminess between 1 and 10 days of storage were not significant.

\section{Lipid oxidation of enhanced beef}

The lipid oxidation of the cooked beef was monitored using thiobarbituric acid reactive substance (TBARS) values. The TBARS value of the enhanced beef was significantly lower than that of the control after 1 day of storage (Table 6). However, it was similar between the control and the enhanced beef after 5 and 10 days of storage $(p>0.05)$. Among the enhanced beef samples, EBS 0.5 had the lowest TBARS value on all storage days, although no significance was found on day 5 of storage. The WMJP showed antioxidant activities through endogenous antioxidants such as polyphenol (5.73 g GAE $/ \mathrm{kg})$ and ergothioneine $(2.53 \mathrm{~g} / \mathrm{kg}$ ) (Table 1). The inhibition of lipid oxidation by the addition of winter mushrooms to meat products has been previously reported. Jo et al. [12] found that the addition of winter mushroom powder to chicken sausages at concentrations of 0.5 and $1.0 \%$ suppressed lipid oxidation. In addition, Choi et al. [13] reported the antioxidant activity of winter mushroom powder on the lipid oxidation of pork sausages at concentrations higher than $1.0 \%$. During storage, TBARS values increased significantly, regardless of treatment. Highly oxidized raw meat is oxidized even more after cooking [7,35]. Therefore, the results of the present study imply that the lipid oxidation of all the raw beef samples gradually increased, although lipid oxidation was measured in cooked beef. However, the TBARS value of EBW 0.5 was not significantly higher after 5 days of storage. This indicates the inhibition of lipid oxidation in the beef enhanced by $0.5 \%$ 
Table 5. Texture properties of the enhanced beef during storage at $4^{\circ} \mathrm{C}$

\begin{tabular}{|c|c|c|c|c|}
\hline \multirow{2}{*}{ Treatment ${ }^{1)}$} & \multicolumn{3}{|c|}{ Storage days } & \multirow{2}{*}{ SEM } \\
\hline & 1 & 5 & 10 & \\
\hline \multicolumn{5}{|l|}{ Hardness $(\mathrm{N})$} \\
\hline \multicolumn{5}{|l|}{ Enhancement } \\
\hline Control & 293.39 & 284.17 & $299.62^{\mathrm{a}}$ & 29.022 \\
\hline Enhanced beef & 254.32 & 273.61 & $258.82^{b}$ & 16.633 \\
\hline SEM & 28.417 & 24.002 & 18.275 & \\
\hline \multicolumn{5}{|l|}{ Source } \\
\hline EBS & $297.58^{\mathrm{a}}$ & 292.23 & 267.63 & 23.748 \\
\hline EBW 0.2 & $266.00^{\mathrm{a}}$ & 264.78 & 258.88 & 34.598 \\
\hline EBW 0.5 & $199.37^{\text {by }}$ & $263.83^{x}$ & $249.97^{x y}$ & 21.649 \\
\hline SEM & 19.722 & 32.008 & 23.883 & \\
\hline \multicolumn{5}{|l|}{ Chewiness } \\
\hline \multicolumn{5}{|l|}{ Enhancement } \\
\hline Control & 81.70 & 81.95 & $95.40^{\mathrm{a}}$ & 11.855 \\
\hline Enhanced beef & 74.76 & 80.00 & $70.72^{b}$ & 5.498 \\
\hline SEM & 8.321 & 9.545 & 7.473 & \\
\hline \multicolumn{5}{|l|}{ Source } \\
\hline EBS & $84.33^{\mathrm{a}}$ & 84.92 & 74.58 & 7.737 \\
\hline EBW 0.2 & $78.67^{\mathrm{ab}}$ & 76.96 & 68.01 & 13.492 \\
\hline EBW 0.5 & $61.26^{b}$ & 78.09 & 69.56 & 6.437 \\
\hline SEM & 7.045 & 12.490 & 7.127 & \\
\hline \multicolumn{5}{|l|}{ Gumminess } \\
\hline \multicolumn{5}{|l|}{ Enhancement } \\
\hline Control & 170.03 & 161.43 & $181.52^{\mathrm{a}}$ & 17.315 \\
\hline Enhanced beef & 146.44 & 159.70 & $152.02^{b}$ & 10.269 \\
\hline SEM & 16.665 & 16.318 & 10.284 & \\
\hline \multicolumn{5}{|l|}{ Source } \\
\hline EBS & $171.90^{\mathrm{a}}$ & 169.10 & 159.50 & 13.300 \\
\hline EBW 0.2 & $152.01^{\mathrm{a}}$ & 155.24 & 147.75 & 23.486 \\
\hline EBW 0.5 & $115.40^{\text {by }}$ & $154.77^{x}$ & $148.81^{x y}$ & 13.056 \\
\hline SEM & 12.292 & 21.958 & 13.053 & \\
\hline
\end{tabular}

${ }^{1)}$ Control: no enhanced beef; EBS: the enhanced beef by $0.5 \%(\mathrm{w} / \mathrm{w})$ sodium chloride; EBW 0.2 : the enhanced beef by $0.5 \%$ $(\mathrm{w} / \mathrm{w})$ sodium chloride and $0.2 \%(\mathrm{w} / \mathrm{w})$ powder of winter mushroom juice; EBW 0.5 : the enhanced beef by $0.5 \%$ (w/w) sodium chloride and $0.5 \%(\mathrm{w} / \mathrm{w})$ powder of winter mushroom juice.

${ }^{a, b}$ Different letters in the same column indicate significant differences between means $(p<0.05)$.

${ }^{x-z}$ Different letters in the same row indicate significant differences between means $(p<0.05)$.

SEM, standard error of the least square mean.

WMJP injection.

\section{Sensory evaluation of enhanced beef}

The enhanced beef received significantly higher scores than the control in all sensory properties (such as color, flavor, taste, texture, and over all acceptability) (Table 7). The improvements to the flavor and taste of the enhanced beef were attributed to the injection of sodium chloride which is a wellknown flavor enhancer in meat [12,36]. In addition, the hardness of the enhanced beef was lower than that of the control after 10 days of storage and this might lead to a high score in texture. 
Table 6. Lipid oxidation (TBARS value) of the cooked enhanced beef during storage at $4^{\circ} \mathrm{C}$

\begin{tabular}{|c|c|c|c|c|}
\hline \multirow{2}{*}{ Treatment $^{1)}$} & \multicolumn{3}{|c|}{ Storage days } & \multirow{2}{*}{ SEM } \\
\hline & 1 & 5 & 10 & \\
\hline \multicolumn{5}{|l|}{ Enhancement } \\
\hline Control & $0.54^{a z}$ & $1.55^{y}$ & $1.92^{x}$ & 0.118 \\
\hline Enhanced beef & $0.42^{b z}$ & $1.51^{y}$ & $1.76^{x}$ & 0.070 \\
\hline SEM & 0.050 & 0.077 & 0.135 & \\
\hline \multicolumn{5}{|l|}{ Source } \\
\hline EBS & $0.49^{\mathrm{az}}$ & $1.54^{y}$ & $1.96^{\mathrm{ax}}$ & 0.106 \\
\hline EBW 0.2 & $0.43^{\mathrm{abz}}$ & $1.52^{y}$ & $1.78^{\mathrm{abx}}$ & 0.075 \\
\hline EBW 0.5 & $0.35^{\text {by }}$ & $1.47^{x}$ & $1.53^{b x}$ & 0.128 \\
\hline SEM & 0.050 & 0.110 & 0.109 & \\
\hline
\end{tabular}

${ }^{1)}$ Control: no enhanced beef; EBS: the enhanced beef by $0.5 \%(\mathrm{w} / \mathrm{w})$ sodium chloride; EBW 0.2 : the enhanced beef by $0.5 \%$ $(\mathrm{w} / \mathrm{w})$ sodium chloride and $0.2 \%(\mathrm{w} / \mathrm{w})$ powder of winter mushroom juice; EBW 0.5 : the enhanced beef by $0.5 \%$ (w/w) sodium chloride and $0.5 \%(\mathrm{w} / \mathrm{w})$ powder of winter mushroom juice.

a,b Different letters in the same column indicate significant differences between means $(p<0.05)$.

${ }^{x-z}$ Different letters in the same row indicate significant differences between means $(p<0.05)$.

SEM, standard error of the least square mean.

Table 7. Sensory properties of the enhanced beef after 10 days of storage

\begin{tabular}{lccccc}
\hline \multirow{2}{*}{ Treatment $^{1)}$} & \multicolumn{5}{c}{ Sensory property } \\
\cline { 2 - 6 } & Color & Flavor & Taste & Texture & Acceptability \\
\hline Enhancement & & & & & \\
Control & $5.34^{\mathrm{b}}$ & $4.12^{\mathrm{b}}$ & $4.19^{\mathrm{b}}$ & $3.86^{\mathrm{b}}$ & $4.24^{\mathrm{b}}$ \\
Enhanced beef & $5.81^{\mathrm{a}}$ & $6.12^{\mathrm{a}}$ & $6.22^{\mathrm{a}}$ & $6.19^{\mathrm{a}}$ & $6.27^{\mathrm{a}}$ \\
SEM & 0.164 & 0.238 & 0.236 & 0.261 & 0.241 \\
Source & & & & & \\
EBS & 5.80 & 6.06 & 6.04 & 5.90 & 6.09 \\
EBW 0.2 & 5.75 & 6.20 & 6.36 & 6.22 & 6.41 \\
EBW 0.5 & 5.89 & 6.06 & 6.22 & 6.45 & 6.27 \\
SEM & 0.187 & 0.296 & 0.313 & 0.330 & 0.305 \\
\hline
\end{tabular}

${ }^{11}$ Control: no enhanced beef; EBS: the enhanced beef by $0.5 \%(\mathrm{w} / \mathrm{w})$ sodium chloride; EBW 0.2 : the enhanced beef by $0.5 \%$ $(\mathrm{w} / \mathrm{w})$ sodium chloride and $0.2 \%(\mathrm{w} / \mathrm{w})$ powder of winter mushroom juice; EBW 0.5 : the enhanced beef by $0.5 \%(\mathrm{w} / \mathrm{w})$ sodium chloride and $0.5 \%(\mathrm{w} / \mathrm{w})$ powder of winter mushroom juice.

a,b Different letters in the same column indicate significant differences between means $(p<0.05)$.

SEM, standard error of the least square mean.

There were no differences in any sensory property scores among the enhanced beef samples. This result implies that the injection of WMJP had no negative effects on the sensorial quality of the enhanced beef. The deterioration of sensorial quality is one of the main problems when natural ingredients are used for quality improvement in meat products because of the unique colors and flavors of the vegetables $[6,7,29]$. However, winter mushrooms have a white color and moderate flavor. Therefore, they have no negative effects on the sensory properties of meat products $[12,13]$.

\section{CONCLUSION}

Enhanced beef, manufactured by the injection of sodium chloride (0.5\%) alone or with WMJP $(0.2 \%$ or $0.5 \%)$, showed no differences from the control in total aerobic bacteria growth or color during storage for 10 days at $4{ }^{\circ} \mathrm{C}$. However, it had lower hardness scores and higher scores in all 
sensory properties than the control. In addition, the use of WMJP resulted in the inhibition of lipid oxidation in the enhanced beef, without the negative effects on the sensorial quality. The findings of the present study suggest that beef can be value-added by manufacturing it as enhanced meat, and the use of WMJP can result in quality improvements in enhanced beef by improving its oxidative stability.

\section{REFERENCES}

1. Ali M, Lee SY, Park JY,Jung S, Jo C, Nam KC. Comparison of functional compounds and micronutrients of chicken breast meat by breeds. Food Sci Anim Resour. 2019;39:632-42.

2. Kim S, Lee HJ, Kim M, Yoon JW, Shin DJ, Jo C. Storage stability of vaccum-packaged dryaged beef during refrigeration at $4^{\circ} \mathrm{C}$. Food Sci Anim Resour. 2019;39:266-75.

3. Lowder AC, Goad CL, Lou X, Morgan JB, DeWitt CAM. Evaluation of a dehydrated beef protein to replace sodium-based phosphates in injected beef strip loins. Meat Sci. 2011;89:491-9.

4. Sebranek JG. Basic curing ingredients. In: Tarté R, editor. Ingredients in meat products: properties, functionality and applications. New York: Springer; 2009. p. 1-24.

5. Faustino M, Veiga M, Sousa P, Costa EM, Silva S, Pintado M. Agro-food byproducts as a new source of natural food additives. Molecules. 2019;24:1056.

6. Lee J, Jo K, Lim Y, Jeon HJ, Choe JH, Jo C, et al. The use of atmospheric pressure plasma as a curing process for canned ground ham. Food Chem. 2018;240:430-6.

7. Lee DG, Lee J, Jo K, Lee CW, Lee HJ, Jo C, et al. Improved oxidative stability of enhanced pork loins using red perilla extract. Korean J Food Sci Anim Resour. 2017;37:898-905.

8. Kumar Y, Yadav DN, Ahmad T, Narsaiah K. Recent trends in the use of natural antioxidants for meat and meat products. Compr Rev Food Sci Saf. 2015;14:796-812.

9. Valverde ME, Hernández-Pérez T, Paredes-López O. Edible mushrooms: improving human health and promoting quality life. Int J Microbiol. 2015;2015:376387.

10. Dong YR, Cheng SJ, Qi GH, Yang ZP, Yin SY, Chen GT. Antimicrobial and antioxidant activities of Flammulina velutipes polysacchrides and polysacchride-iron(III) complex. Carbohydr Polym. 2017;161:26-32.

11. Tang C, Hoo PCX, Tan LTH, Pusparajah P, Khan TM, Lee LH, et al. Golden needle mushroom: a culinary medicine with evidenced-based biological activities and health promoting properties. Front Pharmacol. 2016;7:474.

12. Jo K, Lee J, Jung S. Quality characteristics of low-salt chicken sausage supplemented with a winter mushroom powder. Korean J Food Sci Anim Resour. 2018;38:768-79.

13. Choe J, Lee J, Jo K, Jo C, Song M, Jung S. Application of winter mushroom powder as an alternative to phosphates in emulsion-type sausages. Meat Sci. 2018;143:114-8.

14. Lee S, Jo K, Hur SJ, Choi YS, Kim HJ, Jung S. Low protein digestibility of beef puree in infant in vitro digestion model. Food Sci Anim Resour. 2019;39:1000-7.

15. Jung S, Lee CW, Lee J, Yong HI, Yum SJ, Jeong HG, et al. Increase in nitrite content and functionality of ethanolic extracts of Perilla frutescens following treatment with atmospheric pressure plasma. Food Chem. 2017;237:191-7.

16. Erel O. A novel automated direct measurement method for total antioxidant capacity using a new generation, more stable ABTS radical cation. Clin Biochem. 2004;37:277-85.

17. Oyaizu M. Studies on products of browning reaction: antioxidative activities of products of browning reaction prepared from glucosamine. Jpn J Nutr Diet. 1986;44:307-15.

18. Kalaras MD, Richie JP, Calcagnotto A, Beelman RB. Mushrooms: a rich source of the antioxidants ergothioneine and glutathione. Food Chem. 2017;233:429-33. 
19. Jung S, Nam KC, Jo C. Detection of malondialdehyde in processed meat products without interference from the ingredients. Food Chem. 2016;209:90-4.

20. Ito $\mathrm{H}$, Ueno $\mathrm{H}$, Kikuzaki $\mathrm{H}$. Construction of a free-form amino acid database for vegetables and mushrooms. Integr Food Nutr Metab. 2017;4:1-9.

21. Sun Y, Lv F, Tian J, Ye XQ, Chen J, Sun P. Domestic cooking methods affect nutrient, phytochemicals, and flavor content in mushroom soup. Food Sci Nutr. 2019;7:1969-75.

22. Yu TY, Morton JD, Clerens S, Dyer JM. Cooking-induced protein modifications in meat. Compr Rev Food Sci Saf. 2017;16:141-59.

23. Jo K, Lee J, Lee S, Lim Y, Choi YS, Jo C, et al. Curing of ground ham by remote infusion of atmospheric non-thermal plasma. Food Chem. 2020;309:125643.

24. Reid T, Munyanyi M, Mduluza T. Effect of cooking and preservation on nutritional and phytochemical composition of the mushroom Amanita zambiana. Food Sci Nutr. 2017;5:538-44.

25. Doyle ME, Glass KA. Sodium reduction and its effect on food safety, food quality, and human health. Compr Rev Food Sci Saf. 2010;9:44-56.

26. Jung JT, Lee JK, Choi YS, Lee JH, Choi JS, Choi YI, et al. Effect of rice bran and wheat fibers on microbiological and physicochemical properties of fermented sausages during ripening and storage. Korean J Food Sci Anim Resour. 2018;38:302-14.

27. Kumar P, Chatli MK, Mehta N, Malav OP, Verma AK, Kumar D, et al. Antioxidant and antimicrobial efficacy of sapota powder in pork patties stored under different packaging conditions. Korean J Food Sci Anim Resour. 2018;38:593-605.

28. Puolanne E, Kivikari R. Determination of the buffering capacity of postrigor meat. Meat Sci. 2000;56:7-13.

29. Lee S, Jo K, Jung S. Quality properties of emulsion sausages with added the atmospheric pressure plasma treated extract of Perilla frutescens Britton var. acuta Kudo. Ann Anim Resour Sci. 2019;30:69-78.

30. Fischer K. Drip loss in pork: influencing factors and relation to further meat quality traits. J Anim Breed Genet. 2007;124:12-8.

31. Jo K, Lee J, Lee S, Lim Y, Choi YS, Jo C, et al. Curing of ground ham by remote infusion of atmospheric non-thermal plasma. Food Chem. 2020;309:125643.

32. Faustman C, Cassens RG. The biochemical basis for discoloration in fresh meat: a review. J Muscle Foods. 1990;1:217-43.

33. Aktas N, Aksu MI, Kaya M. The influence of margination with different salt concentrations on the tenderness, water holding capacity and bound water content of beef. Turk J Vet Anim Sci. 2003;27:1207-11.

34. Fadiloğlu EE, Serdaroğlu M. Effects of pre and post-rigor marinade injection on some quality parameters of longissimus dorsi muscles. Korean J Food Sci Anim Resour. 2018;38:325-37.

35. Ferioli F, Cabonia MF, Dutta PC. Evaluation of cholesterol and lipid oxidation in raw and cooked minced beef stored under oxygen-enriched atmosphere. Meat Sci. 2008;80:681-5.

36. Stanley RE, Bower CG, Sullivan GA. Influence of sodium chloride reduction and replacement with potassium chloride based slats on the sensory and physico-chemical characteristics of pork sausage patties. Meat Sci. 2017;133:36-42. 